\title{
Synthesis of activated carbon sand their application in the synthesis of monometallic and bimetallic supported catalysts
}

\author{
DALILA BOUSBA ${ }^{(1)^{*}}$, CHAFIA SOBHI ${ }^{(1)}$, AMNA ZOUAOUI $^{(1)}$, SOUAD BOUASLA $^{(2)}$ \\ ${ }^{(1)}$ Department of Petrochemical Industry and Process Engineering, Faculty of Technology Ftch, \\ Skikda, Algeria \\ (2)Higher Normal School for Technological Education (ENSET), Azzaba, Skikda, Algeria \\ “d.bousba@univ-skikda.dz, ${ }^{*}$ c.sobhi@univ-skikda.dz, zouaoui amna@yahoo.fr, \\ souad2004 chem@yahoo.fr
}

\begin{abstract}
Biomass-derived porous carbons are attractive materials for the synthesis of carbon-supported catalysts, carbonaceous catalysts are environmentally benign and could provide an important competitive advantage as compared to existing heterogeneous catalysts, however the surface properties of carbon materials and excellent physical and chemical properties are compatible with diverse catalysis reactions including organic transformations. Currently, activated carbons are one of well known carbonaceous materials for their catalytic properties and for use as support in heterogeneous catalysis. The supported catalysts have been successfully used in the chemical industries for a long time, in which carbon supported catalysts have allowed to a new chemical catalytic process, on the other hand Heterogeneous catalysis plays a key role in the manufacture of essential products in different fields. In this paper we are present comparative study, between two main different methods for activated carbons (ACs) preparation namely, physical and chemical activations. Latter was prepared from agro-industrial biomass and used as a support to prepare monometallic (dry impregnation and excess impregnation) and bimetallic catalyst (successive impregnation and co impregnation).
\end{abstract}

Keywords: Activated carbons, chemical activation, Physical activation, supported catalyst.

\section{INTRODUCTION}

As the world's population grows, the need for energy and water increases. This corresponds to an economical growth and development, which leads to a huge rise in the use of chemical compounds, industrial compounds, agricultural wastes which pose the risk of polluting the air and the existing water sources [1-2]. The river, lake, and ground water sources are contaminated due to fertilizers, pesticides, antibiotics, dyes, heavy metals from the industry which results in diseases like cancer, skin defect, kidney damage, liver problems, etc.[3]. On the other hand, the burning of fossil fuel generates the greenhouse (GHG) and harmful gases like $\mathrm{CO}_{2}, \mathrm{CH}_{4}, \mathrm{H}_{2} \mathrm{~S}, \mathrm{NO}_{2}$ to the environment which are increasing with the current energy demand[4].

Therefore, it is highly recommended to find cheap and environmentally friendly adsorbent to eliminate the pollutants from water and air. Different techniques have been developed over the years, to purify the water contamination and the air, the most widely used is the adsorption technique [5]. Owing to its good properties such as cost-effective, easy to operate, eco friendly for environment, low health risk, and non-destructive process [6]. Among many activated carbon (AC) is the most used and well-known adsorbent, its production from agricultural by-products has both economic and environmental impacts, as it converts unwanted, low-value agricultural waste to high-value useful adsorbent [7]. Therefore, low cost residues with high carbon and low inorganic content can be considered as starting materials for the production of activated carbon [8]. Some of the most used are agro-industrial byproducts, which are characterized by their renewability, high mechanical strength, cheapness, abundance, as well as low ash contents. In fact, several studies have reported the utilization of agricultural wastes biomass residues in $\mathrm{AC}$ production such as rice husk [9] as coal, jujube seeds [10], sawdust [11], tropical wood [12], palm shells [13], durian peel [14], corn cobs [15], coconut shells [16], walnut shells [17], watermelon [18], tobacco stems, bean husks, hazelnut shell, banana peels, mangosteen shells and many more. Another major application for ACs, that they can be used as a green support for catalysts or as a catalyst itself [19]. 


\section{ACTIVATED CARBONS}

\section{A. Activated carbons}

Active carbons (AC) are carbonaceous porous materials with large surface area, high porosity, and rapid adsorption capabilities. They are used for several purification applications in different industrial processes, including wastewater treatment, gas cleaning processes, and metal removal from waste streams. AC has also been used as support for heterogeneous catalysts] or as a catalyst itself

\section{B. Experimental}

Activated carbons could be produced in many different ways methods, which could be classified in two main types, physical activation or chemical activation [36].

Prior to the carbonization step, the biomass was selected, crushed, dried under temperature between $100^{\circ} \mathrm{C}-110^{\circ} \mathrm{C}$ to eliminate water, then sieved to get uniform particles size, next the crushed samples were subjected to carbonization in a furnace under temperature $\left(400^{\circ} \mathrm{C}-900^{\circ} \mathrm{C}\right)$ and temps then cooled in inert atmosphere. The carbonisate samples was subjected to physical activation (with $\mathrm{CO}_{2}$ ) or chemical activation [20, 23, 28].

\section{Chemical activation}

In Chemical activation, the raw material is impregnated with a chemical agent $\left(\mathrm{H}_{3} \mathrm{PO}_{4}\right.$, $\mathrm{ZnCl}_{2}, \mathrm{KOH}, \mathrm{NaOH}, \mathrm{K}_{2} \mathrm{CO}_{3}$, etc), before thermal treatment, they acts by dehydrating agents and oxidants [21, 23, 24].

\section{Physical activation}

Physical activation is a two-stepprocess, the first step consists of a carbonization of the precursors at high temperature under inert atmosphere (usually $\mathrm{N}_{2}$. The second one involves activation at high temperature in oxidizing atmosphere, such as air, steam and $\mathrm{CO}_{2}$, without any other reactants added in the precursor [37].

Physical and chemical activations are common techniques to prepare ACs. Chemical activation is usually preferred due to the simplicity, shorter activation time, higher yield, lower temperature and better development of the porous structure [24]. The preparation process of activated carbon from walnut shell was showed in the fig. 1.

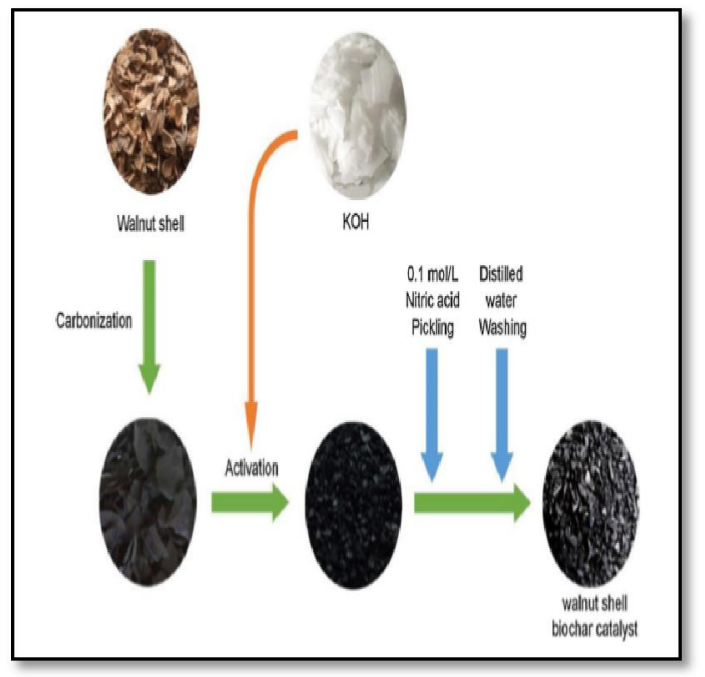

Fig. 1. Preparation process of walnut shell biochar catalyst [27].

This treatment of the raw material before pyrolysis creates macropores, mesopores, and micropores on and inside the solid's surface [35].

Carbonization temperature plays a significant role on the activated carbon yield [36].

Several studies have analyzed and discussed the properties of Activated carbon prepared from the biomass. (PiotrNowicki, Robert Pietrzak, Helena Wachowska, 2009) have been prepared activated carbon from walnut shell by chemical and physical activation. The results presented showed that textural parameters of the activated carbon samples obtained from walnut shells are determined by the activation method and activation temperature for chemical activation. The samples activated by $\mathrm{KOH}$ have much better textural parameters than those activated by $\mathrm{CO}_{2}$. Many scientists studied the preparation methods of $A C$ to obtain the best parameters of AC, (Joana. Goscianska et al., 2012; Xin Song et al., 2016) have been prepared AC from walnut shells by chemical activation, They have changed the conditions of preparation ( temperature of carbonization, temperature of activation and ratio of activating agent), ( Xinsong et al., 2017) obtained very good results ; high specific area $\left(1184 \mathrm{~cm}^{2} / \mathrm{g}\right)$ and high pore volume $\left(0,50 \mathrm{~cm}^{3} / \mathrm{g}\right)$, (YanpingGuo, David A.Rochstraw; 2006) prepare AC from pecan nutshells, they obtained specific area $\left(1130 \mathrm{~cm}^{2} / \mathrm{g}\right)$ and micropore volume $(0.43$ $\mathrm{cm}^{3} / \mathrm{g}$ ) (temperature of carbonization $500^{\circ} \mathrm{C}$ ). Tab.1. Show the difference between conventional activation methods The quality of the $A C$ can be measured by superficial 
area, granulometry, dominant pore type, and adsorption indicators, among others.

The factors that are most important in determining $A C$ quality are carbonization time, carbonization temperature and the activation ratio $(R)$, which is the mass ratio of activator to raw material [35].

\section{METHODS AND DISCUSSIONS}

Both activations methods gaves activated carbons with particulars properties. The destined use and the raw precursor used to produce ACs are the determination key of ACs characteristics. The main advantages of using a chemical activation method are higher final carbon yields, a one-step process, generally lower activation temperatures, and an easier adjustment of porosity

\section{PREPARATION OF SUPPORTED MONO METALLIC CATALYSTS}

Preparation method of supported catalysts significantly affects their activity, selectivity, and life time. These methods have been recently introduced as simple technique to maximize the interaction between support and a catalytic metal precursor and can give more control over particle size and size distributions [29].

Supported monometallic catalysts are generally prepared from a metal salt or an organometallic compound by (Simple Impregnation, Precipitation Deposit) [25].

Impregnation is the simplest and most widespread method for catalyst preparation. Using an amount of the precursor solution in excess of the pore volume of the support, is termed wet impregnation (WI).

Limiting the solution amount to just fill the pore volume is called dry orincipient wetness impregnation (DI) [29].

\section{1 dry impregnation DI}

Dry impregnation (pore filling) is the simplest, least expensive and most prevalent way to prepare supported metal catalysts. By this method, a desired metal precursor dissolved in water and the solution is added to an oxide or carbon support in the amount just to fill the pore volume of the support [26].

\section{2 excess impregnation (wet impregnation) WI}

In this method, the volume of the solution is greater than the pore volume. the interactions between the metal precursor and the support is strong [25].

A schematic illustration of impregnation method is shown in fig.2.

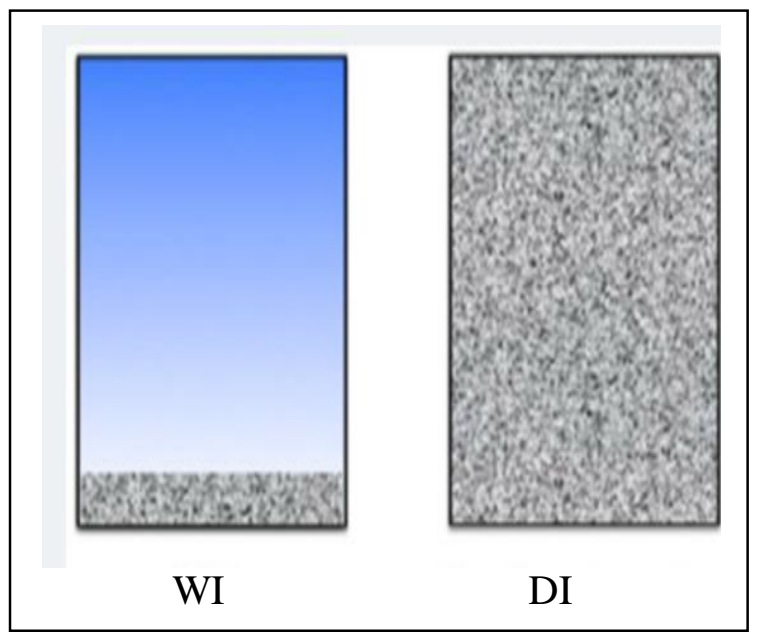

Fig. 2. wet impregnation IW and dry impregnation DI [26]

\subsection{Precipitation deposit DP}

The DP method involves the conversion of a highly soluble metal salt precursor into a lesssoluble substance which precipitates only on the support and not in solution. This process is achieved by a change in solution $\mathrm{pH}$, addition of a precipitation agent, addition of a reducing agent, or change in the concentration of a complexation agent.

There are two main conditions which must be fulfilled to make sure that the precipitation occurs only on the support instead of in solution: a strong interaction between the soluble metal precursor and the surface of the support and controlled concentrations of the precursor in solution to avoid spontaneous precipitation.

By this method, the metal salt solution is getting in contact with the support, and then is precipitated by addition of a base (for example $\mathrm{KOH}$ ).

The mixture is kept stirring with or without heating. Then the solid is recovered and washed with water. After the deposition by impregnation or precipitation deposition, the catalysts are activated by different heat treatments [25].

\section{PREPARATION OF SUPPORTED BIMETALLIC CATALYSTS}

Conventional preparation methods by coimpregnation or Successive impregnation. 


\subsection{Successive impregnation}

In the first step, the monometallic catalyst is prepared by impregnation of the metal salt of the first metal, then it is activated by heat treatment.

The bimetallic catalyst is then prepared in the same way, by impregnating the metal salt of the second metal with the monometallic catalyst synthesized previously, followed by activation [25].

\subsection{Co-impregnation}

The metal salts of the different metals are impregnated simultaneously on the support. The impregnated support is dried and activated [25].

In order to get an insight on the effect of the synthesis method on catalysts, we considered the work of some researchers.(PrathanKittisakmontree et al. 2012) prepared $\mathrm{Pd}-\mathrm{Au} / \mathrm{TiO}_{2}$ catalysts by combination of wetness impregnation and deposit- precipitation, (N.K.Gamba et al. 2012) .

Prepared $\mathrm{Au}-\mathrm{Cu}$ bimetallic catalysts by wet impregnation and deposition precipitation the results indicated that catalyst prepare by DP better than catalyst prepare by wet impregnation, (P.Chantaravitoon et al..2003) prepared Pt- $\mathrm{Sn} \quad / \mathrm{AlO}_{3}$ catalyst by impregnation and co-nmpregnation, the result showed high dispersion by coimpregnation while lower dispersion by sequential impregnation, (M.Garcia- Diéguez et al.2010) and (A. Abdedayem et al. 2014) prepared their supported catalysts by wetness impregnation and they obtained good results.

In catalysis, the materials prepared must be analyzed to confirm its structure and determine its characteristics and physicochemical properties. Among these, the most important techniques are: X-Ray Diffraction (XRD), Programmed Temperature Reduction (RTP), Physisorption of $\mathrm{N}_{2}$, Infrared Spectroscopy (IR), Raman Spectroscopy, Scanning Electron Microscopy coupled with Energy Dispersion Analysis (MEB-EDX) [20-24]

\section{CONCLUSION}

In order to prepare a valuable and low cost adsorbent; activated carbons; the use of cheap raw materials with high rate of carbon as well as low inorganic, are the best choice both economically and environmentally. The high demand of activated carbon is due to its particular properties like large micro porosity, high specific surface area associated to a wide spectrum of applications.

The presence of activating agents or carbon dioxide and carbonisation conditions affects the development of pore structures. Its texture characteristics and surface properties depend on the raw material and on the method used for its preparation.

Table1 Conventional activation methods and main process parameters [34].

\begin{tabular}{|c|c|c|c|}
\hline 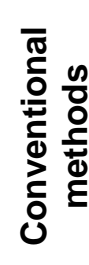 & 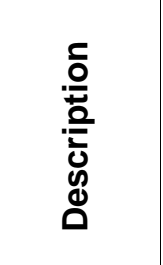 & 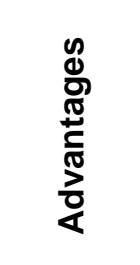 & 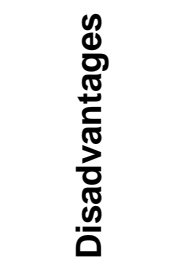 \\
\hline 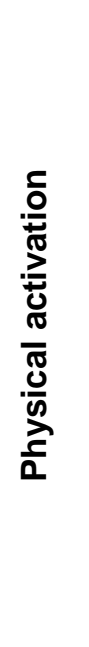 & 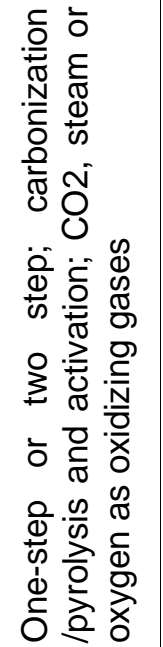 & 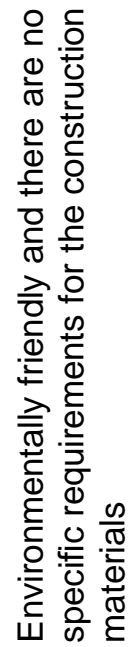 & 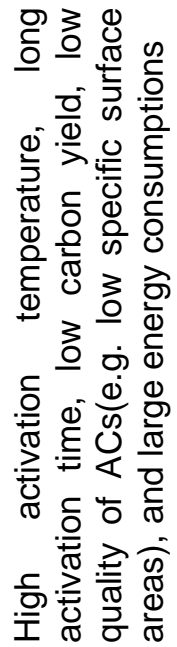 \\
\hline
\end{tabular}




\begin{tabular}{|c|c|c|c|}
\hline 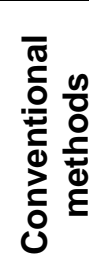 & 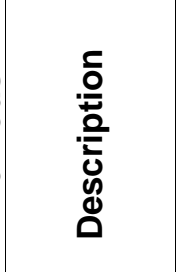 & 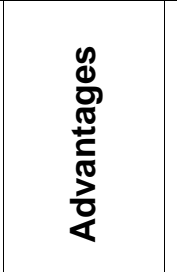 & 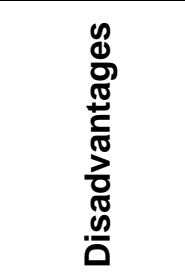 \\
\hline & 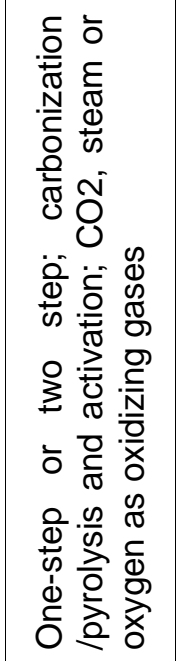 & 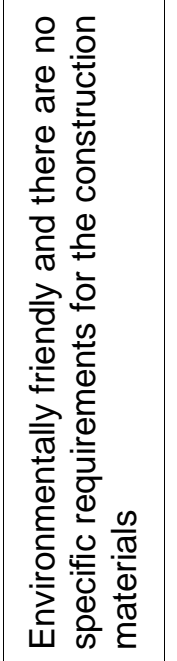 & 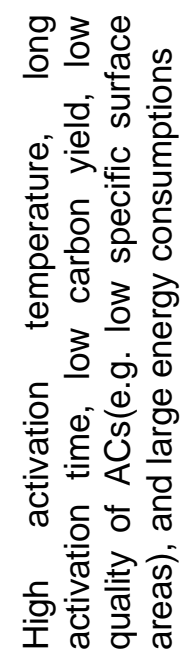 \\
\hline 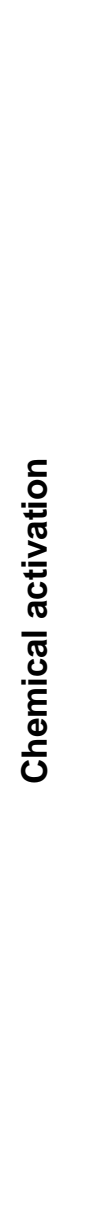 & 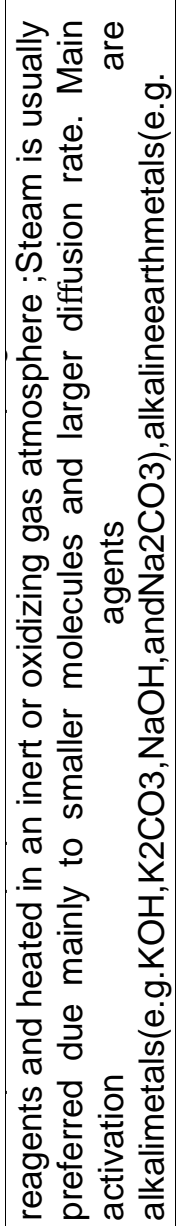 & 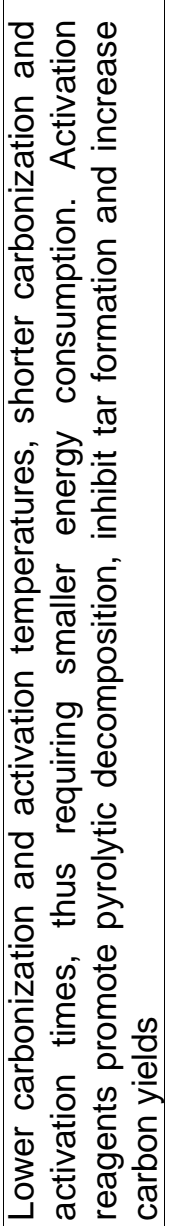 & 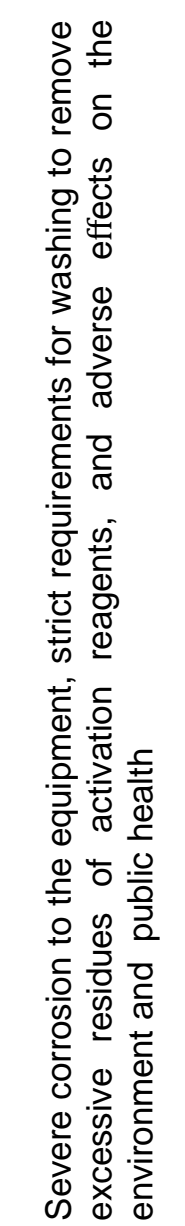 \\
\hline
\end{tabular}

\section{ACKNOWLEDGMENT}

This work was supported by the Ministry of Higher Education and Scientific Research of the Algerian
Government [projects PRFU Code: A16N01UN210120190005

\section{REFERENCES}

[1] M.A. Mohammad Razi, A. Al-Gheethi,M. AlQaini, \& A. Yousef, A" Efficiency of activated carbon frompalm kernel shell for treatment of greywater", ArabJournal of Basic and Applied Sciences,25(3), 103110, 2018.

[2] N. Le-Minh,E.C. Sivret, A.Shammay, \&R.M. Stuetz,"Factors affecting the adsorption of gaseous environmen-talodors by activated carbon",Environmental Science and Technology,48(4),341-375, 2018.

[3] T. Ahmad\&M. Danish," Prospects of banana waste utilization in wastewater treatment" Journal of Environment Management,206, 330-348, 2018.

[4] A.Ahmed,M.S. Abu Bakar, A.K. Azad, R.S Sukri, \& T.M.I Mahlia," Potential thermochemical conversion of bioenergy from Acacia species in Brunei Darussalam", Renewable and Sustainable EnergReviews,82,3060-3076, 2018.

[5] A.A.Oladipo, A.O. Ifebajo, N. Nisar\& O.A. Ajayi," High-performance magnetic chicken bone-based biocharfor efficient removal of rhodamine-B dye and tetracyc-line: Competitive sorption analysis. Water Science andTechnology", A Journal of the International Association onWater Pollution Research,76(2), 373-385, 2017.

[6] V. Balasundram, N. Ibrahim,R.M Kasmani, ,M.K.A Hamid, R. Isha, H. Hasbullah\& R.R Ali,"Thermogravimetric catalytic pyrolysis and kinetic studiesof coconut copra and rice husk for possible maximumproduction of pyrolysis oil", Journal of Cleaner Production,167, 218228. 2017.

[7] O. A. Ekpete and M. Horsfall Jr., "Preparation and characterization of activated carbon derived from fluted pumpkin stem waste (Telfairiaoccidentalis hook f),"Research Journal ofChemical Sciences,vol.1,no.3,pp.10-17,2011.

[8] M.J. Munyoz-Guillena, A. Linares-Solano and C. Salinas-Martinez de Leccea. Determination of calorific values of coals by differential thermal analysis. Fuel, 71, 579583,1992

[9] J. Alvarez,G. Lopez ,M. Amutio, J.Bilbao,M. Olazar"Upgrading the rice husk char obtained by flash pyrolysis for the production of amorphous silica and high quality activated carbon". Bioresour. Technol,2014;170:132-7.

[10] W. Bae, J. Kim , "Chung "Production of granular activated carbon from foodprocessing wastes (walnut shells and jujube seeds) and its adsorptive properties". J. Air Waste Manage. Assoc, 2014;64(8):879-886.

[11] S.M. Kini, M.B. Saidutta, R.V. Murty, S.V.Kadoli,"Adsorption of basic dye from aqueous solution using $\mathrm{HCl}$ treated saw dust (Lagerstroemia microcarpa)", International 
Research Journal of Environment Sciences ,2015;2(8):6-16.

[12] J. Acharya J.N.Sahu,C.R. Mohanty,B.C. Meikap,"Removal of lead (II) from wastewater by activated carbon developed from Tamarind wood by zinc chloride activation". Chemical Engineering Journal 2009;149:249-262.

[13]

[14] A.B.M.Noor,M.A.B.M.Nawi,"Textural characteristics of activated carbons prepared from oil palm shells activated with $\mathrm{ZnCl} 2$ and pyrolysis under nitrogen and carbon dioxide", Journal of Physical Science,2008;19(2):93104.

[15] K. Nuithitikul, S. Srikhun, S. Hirunpraditkoon," Influences of pyrolysis condition and acid treatment on properties of durian peel-based activated carbon",BioresourTechnol,2010;101(1):426429.

[16] W. Jonglertjunya ,"Biosorption of Lead (II) and Copper (II) from Aqueous".,Chiang Mai J. Sci, 2008;35(1):69-81.

[17] R. Shaheed,C.H. Azhari, A.Ahsan, W.H.M.W Mohtar. Production and "characterisation of low-tech activated carbon from coconut shell", J. Hydrol. Environ. Res,2015;3(1):6-14.

[18] J. Yang , K. Qiu ," Preparation of activated carbons from walnut shells via vacuum chemical activation and their application for methylene blue removal", Chemical Engineering Journal 2010;165:209-217.

[19] K. Banerjee, S.T Ramesh, R. Gandhimathi, P.V Nidheesh, K.S. Bharathi KS," A novel agricultural waste adsorbent, watermelon shell for the removal of copper from aqueous solutions", Iran. J. Energy Environ, 2012;3(2):143-56.

[20] L.-R. Radovic, C. Mora-Vilches, A.J.A. Salgado-Casanova, Chin. J. Catal.35 (2014) 792.

[21] V.Gomez-Serrano, E. M.Correa, M.F.G.alez,M.A.Franco and A. M. Garc'ıa, "Preparation of activated carbons from walnut wood: a study of microporosity and fractal dimension"Smart Mater. Struct, 363368, 2005.

[22] J. Goscianska, I. Nowak, P.Nowicki, R. Piertrzak,"the influence of silver on the physicochemical and catalytic properties of activated carbons", Chemical Engineering Journal,189- 190, 422- 430, 2012.

[23] V. G. Serrano, E. M. C.Correa, M.F.Gonzalez, M.F.A.Franco and A.M.Garc'ıa, "Preparation of activated carbons from walnut wood: a study of microporosity and fractal dimension",Smart Mater. Struct, 14, 363-368, 2005.

[24] L. Fan, J. Chen, J. Guo, X. Jiang, W. Jianga," Influence of manganese, iron and pyrolusite blending on the physiochemical properties and desulfurization activities of activated carbons from walnut shell", Journal of Analytical and AppliedPyrolysis 104, 353360, 2013.

[25] W. Ao, J. Fu, X. Mao, Q. Kang, C. Rana, Y. Liua, H. Zhang, Z. Gao, Jing Lia,b, G Liu, J. Dai, "Microwave assisted preparation of activated carbon from biomass", Renewable and Sustainable Energy Reviews, 92, 958979, 2018.

[26] B.Tapin, 'Preparation andPreparation and characterization of bimetallicRe-Pd / TiO2 catalysts for the hydrogenation of succinicacidfrombiomass", theses.univpoitiers.fr, 2012.

[27] X. Zhu, H.Cho, M. pasupong, J.R. Regalbuto "ChargeEnhanced dry inpregnation: a simple way to improve the preparation of supported metal catalysts", ACS Catal, 3, 625-630, 2013.

[28] Song, K. Li, P. Ning, C. Wang, X. Sun, L. Tang, H. Ruan, S. Han, "Surface characterization stusies of walnut- shell biochar catalysts for simultaneously removing of organic sulfur from yellow phosphorus tail gas", Applied Surface Science, 425, 130-140, 2017.

[29] P. Nwikcki, R.Pietrzak, H. Wachwscka, "Sorption properties of active carbons obtained from walnut sells by chemical and physical activation"CatalysisToday, 150 107114, 2010.

[30] B. A.T. Mehrabadi, S. Eskandari, U. Khan, Rembert D. White, John R. Regalbuto,"A Review of Preparation Methods for Supported Metal Catalysts", Advances in catalysis, 61, ISSN 0360-0564, 2017.

[31] P.Kittisakmontree, B.Ponthawornsakun, H.Youchida, S.Fujta, M.Arai, J.Panpranot,"The liquid-phase hydrogenation of 1-heptyne over $\mathrm{Pd}$-Au /Tio2 catalysts prepared by the combination of incipient wetness impregnation and deposition precipitation", Journal of Catalysis, 297, 155-164, 2013.

[32] P. Chantaravitoon, S. Chavadej, J. Schwank, "Pt-Sn/Al2O3 catalysts: effect of catalyst preparation and chemisorption methods on $\mathrm{H} 2$ and $\mathrm{O} 2$ uptake", Chemical Engineering Journal, 98, 99-104, 2004.

[33] M.Garcia-Diéguez, E.Finocchio, M.A.Larrubia, L.J.Alemany, G.Busca,

[34] "Characterization of alumina-support Pt, Ni and PtNi alloy catalysts for the dry reforming of methane" Journal of Catalysis 274, 11-20 , 2010.

[35] A. Abdedayam, M.Guiza, A. Ouederni, Copper supported on porous activated carbon obtained by wetness impregnation: Effect of preparation conditions on the ozonation catalyst's characteristics,C. R. Chimie, 2014

[36] Y. Guo, D. A. Rockstraw, "Physicochemical properties of carbons prepared from pecan shell by phosphoric acid activation", BioresourceTechnology, 98, 1513-1521, 2007. 
[37] V. Bello-Huitle, P. Atenco-Fern'andez and R. Reyes-Mazzoco," Adsorption studies of methylene blue and phenol onto pecan and castile nutshells prepared by chemicalActivation",RevistaMexicana de IngenieríaQuímica, 9, 3, 313-322, 2010:
[38] M. A. Yahya, C.W. Zanariah C. W. Ngah ,M. A. Hashim\& Z. Al-Qodah,'Preparation of ActivatedCarbonfromDesiccatedCoconutResi due by Chemical Activation withNaOH'Journal of Materials Science Research, 5, No. 1; 2016. 